\title{
RESEARCH OF BALANCE OF FORCES AFFECTING ON THE GRAIN BETWEEN CYLINDRICAL ROLLS OF SMALL-SIZE FEED MINCING UNIT
}

\section{Gulnara Mamadova}

Azerbaijan State University of Economics (UNEC), Baku, Republic of Azerbaijan.

ART ICLE INFO

\section{Article History}

Received: April 21, 2021

Revised: July 1, 2021

Accepted: July 30, 2021

\section{Keywords}

Analytical solutions

Balance of forces

Corn-flattening mill

Farming enterprises

Feed mincing unit
A B S T RA C T

The conducted research is devoted to the study of the balance of forces affecting on the grain between cylindrical rolls of the small-size feed mincing unit used in farming enterprises. It is established that substantiation of design and process parameters of the feed mincing units, plotting the analytical dependences and solution of process tasks are among the most important factors in manufacture of various versions of the unit. Using the obtained analytical solutions increase the efficiency of the works performed in this field. Recently, in the countries where the grain is harvested using the two-phase method, it is performed during the milk maturity period by pressing with special grinding machines immediately in the field, adding the conserving agent, preserving, packing into polyethylene bags, and then storing tight during winter. It is proven that the production costs for such nutritive grain feed reduce by $30 \%$ in contrast to the usual method. The grain stored in such a way is taken out of the grain bags and used directly for feeding the animals. The research work aimed at substantiation of design and process parameters of the small-size, low energy-intensive units for feed oakum production functioning on the basis of the grinding method in the conditions of farming enterprise is of great relevance. The work purpose is to study the balance of forces affecting on the grain between cylindrical rolls of the small-size feed mincing unit.

Corresponding Author: Gulnara Mamadova

Email: gul-mamadova7488-1@kpi.com.de

(C) The Author(s) 2021.

\section{INTRODUCTION}

Pressing is one of the most widely used processes in food, consumer goods and heavy industry. In heavy industries, it is used in design of machines for production of metal plates of various thickness, in the rolling of polyethylene, plastic, rubber and similar materials under appropriate conditions, in grinding stone and sand in stone and sand pits, in grinding various crystals in mining operations, etc. The devices and machines operating on the basis of technology (Ankulenko, 2003) are used in the consumer goods and food industries for production of flour, confectionery, etc. (Afanasyev, 1983). In agriculture, the cylindrical drum grinders are mainly used for pressing and grinding the grains, pesticides and fertilizers that have hardened during storage (Rudovsky et al., 2019). For the first time, the grain grinding by pressing was investigated with dry grain pressing (Baldanov and Khusaev., 2002). In his research (Mammadova and Bagirov., 2008), the author demonstrates that to stretch the grain caught between two drums, the friction force generated from the surface of the drum must be equal or less than the force pulling the grain between the two drums. According to the source (Andrianov, 1972), the optimal diameter of the drums pressing the grain can be taken within the range of $150 \ldots 450 \mathrm{~mm}$ in the mentioned conditions. 
The experience shows that to convert the grain into grits, the grain grinding with pressing reduces the losses generated by spraying and increases the yield of the final product from a single mass if to compare with other grinding methods. This process provides for reducing the energy consumption for single mass grinding (Babaev, 2003). The experience shows that using the grain in the pressed form is well digested both by human and animal organism by increasing the fat and milk quantity by $10-20 \%$ (Baranov, 2000). That is why grinding the grains either in dry or somewhat wetted form and using them as food products is today of great interest for scientists and designers as a prospective area.

To achieve the goal, the following objectives were set:

- to substantiate the design and process parameters of the small-size, low energy-intensive unit for feed oakum production functioning on the basis of the flattening principle and used in the farming enterprises;

- the theoretical research work is aimed at plotting the analytical dependences for the selected design and process option of the roll flattening mill;

- theoretically to research and substantiate the reasonable design of the roll flattening mill to ensure the feed oakum quality with less power consumption.

\section{MATERIALS AND METHODS}

To prepare the nutritive grain feed in the diet balance of animals and poultry, various feed mincing machines are used (KDM-2, KDY-2, AH-DDP, DDM, DM-440y). The capacity of these machines varies from 2 to $8 \mathrm{t} / \mathrm{h}$. Their weight makes from $240 \mathrm{~kg}$ to $2,500 \mathrm{~kg}$. The required energy is 7-100 kW. These machines are suitable for large animal feed plants and shops. Their use in small farming enterprises is not efficient. One of the methods of the nutritive grain feed preparation flattening with pressing. Using this method, the grain is flattened in dry or wet form. In these units, the final product of thermal couple and mechanically processed grain is in the form of oakum that the animals enjoy and that is well digested. The roll mills VMP or corn-flattening mills P3 are used as process equipment. The experience shows that the companies producing the feed machines considering the current needs of the farming enterprises have represented the small-size versions of the cornflattening mills in the technical market (P3-3, DP3-02).
Their hourly capacity varies from $200 \mathrm{~kg}$ to $1 \mathrm{t}$. When the grains are pressed and hydrothermally processed at $60-750^{\circ} \mathrm{C}$, the starch viscosity in its content increases, and gelatinization occurs, as a result, the starch shell is destroyed, and the nutrients contained in the grain become more beneficial for animals. Using this method, the digestion efficiency of barley and corn from hard-togrind and hard-to-digest grains increases to $13 \%$ (Deshko, 1976). In practice, it was found out that at the beginning of the process, the grain temperature gradually rises, the steam effecting on the grain condenses, and then the moisture penetrates into the grain through diffusion. To obtain moisture with the required intensity, it is necessary to increase the steam flow rate or the amount of steam per unit of material (Baranov, 1999). To dry one ton of grain with a moisture content of 30-35\%, 30 litres of liquid fuel are used. More than 60 million tons of the feed grain are dried annually in the Russian Federation. About 2 million tons of fuel are used for this purpose (Deshko and Kukta., 1991).

\section{RESULTS AND DISCUSSION}

An increase in the moisture content of the grain material by more than $15 \%$ increases the energy consumption of the grinding process, and the processing efficiency is significantly reduced. It was found out that when the moisture content increases from $15 \%$ to $17 \%$ when it is ground on the existing hammer feed mincing unit, the machine capacity decreases by $2.5-3.0 \%$, the degree of grinding decreases by 1.3-1.6 times, and the energy intensity increases from $7-9 \mathrm{~kW} / \mathrm{h}$ to $21-23 \mathrm{~kW} / \mathrm{h}$ (Pilipenko, 1981).

Experiments of different scientists and researchers have proven that moist and pressed canned grains have more nutritional value. It was found out that when grinding with pressing, the nutritional value of $1 \mathrm{~kg}$ of feed increases by more than $4.4 \%$ as compared to conventional grinding, i.e., hammer grinding (Baranov, 2004). The maximum decrease in the degree of the curve occurs at a moisture content of $28-32 \%$, and after that, although the moisture content increases, the deformation force changes with very little intensity. The energy intensity of pressing grain with moisture close to the moisture condition (i.e., 14\%) is different for different cereals (Dorofeev and Sundeev., 1978), and it depends on the type of the grain and growing conditions. For the horizontal movement of the grain, there should be a mechanism that creates the forced flow and 
provides forced supply of the grain between the drums. The grain, at the velocity of $\mathrm{V}_{\mathrm{d}}$, enters between drums rotating towards each other. Before entering between the drums, the grain thickness is $\mathrm{H}$, and the distance between the drums is $\mathrm{H}$, and the thickness after leaving the drum is ho. The process flow chart for grain pressing and passing between two drums in the horizontal direction is shown (Figure 1). When the grain enters the

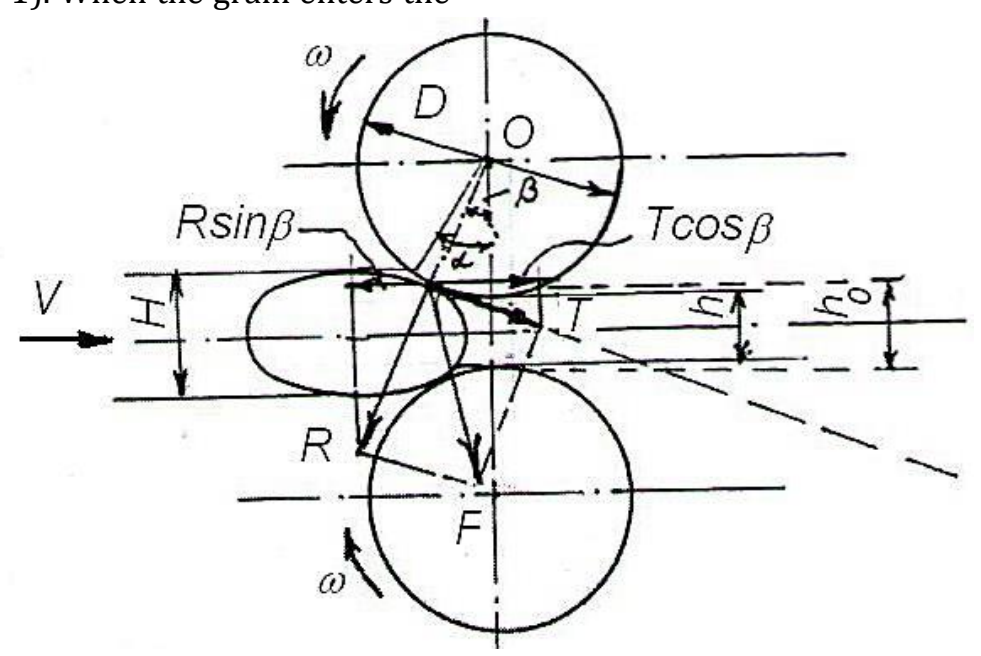

drums, its capturing, pulling and compression can occur only if the distance between $\mathrm{h}<\mathrm{H}$ and the angle $\varphi$ that characterizes the coefficient of friction over the drum surface is less than the grain capture angle $\beta$.

$\varphi<\beta$. To satisfy these conditions, it is important to find the drum diameter (Figure 1):

$(H-h) / 2=(D / 2) \cos \alpha$,

Figure 1. Grinding process flow chart for grain pressing with horizontal delivery.

Hence:

$D=(H-h) /(1-\cos \alpha)$,

Using this formula, it is difficult to calculate the diameter by reference because it is almost impossible to determine the angle $\alpha$ itself. If the point of contact $A$ at the moment of grain capture in the drum is taken as the angle $\beta$ between the lines connecting the center of the drums with a straight line, in order to capture the seeds and pass them into the drum joints, this angle $\varphi$ should be less than the angle of friction of the seeds over the drum.

On the other hand, in order to keep the seeds between the drums, the reaction $R$ and the friction substitute $F$ which act on the seeds during capture should be directed towards the drums. In this case $(\varphi>\beta)$, the drums capture the seeds and pull them by pressing a safe manner. If $(\alpha=\beta)$, the seeds roll along the surface of the drums and do not enter the intermediate distance.

This is the first case when these three cases are of practical importance, and for correct direction of the forces $T$ and $R$ towards the drum $F$, the following condition should be satisfied

$T \cos \beta>R \sin \beta$,

where: $T$ is the friction force equal to the product of the force of reaction $R$ and friction coefficient $f$ :

$T=R f$,

on the other hand:

$f=\operatorname{tg} \varphi$,

thus,

$R \cos \beta>R \sin \beta$

$f>\operatorname{tg} \beta$

$\operatorname{tg} \varphi>\operatorname{tg} \beta$ ขә $\varphi>\beta$.

The angle $\beta$ shown in the above expressions and illustrated in Figure 2 is called inlet angle $\beta$. It may vary from $\alpha / 2$ to $\alpha$. The most hazardous case is when $\beta=\alpha$, and the best one is when $\beta=\alpha / 2$ for $\beta=\alpha$, the following can be written:

$D=\frac{H-h}{1-\cos \beta}$.

It is known that $\cos \beta=\sqrt{1+\mathrm{T}^{2} \beta}$, that is why the final expression can be written as follows:

$D=(H-h) /\left(1-\sqrt{1+\operatorname{tg}^{2} \beta}\right)$,

If we write this formula in the form of inequation, it can be written considering the grain capture and pulling to the drums and pressing:

$D>(H-h) /\left(1-\sqrt{1+\operatorname{tg}^{2} \beta}\right)$,

The grain can be delivered between the drums in vertical manner, i.e. By the grain flow (Figure 2). 
Irrespective of the method of vertical grain delivery, the grain capture and pressing between the rolls will be performed according to the above-mentioned conditions. Figure 2 shows the scheme that characterizes the grain capture and pressing between the drums in the vertical position.

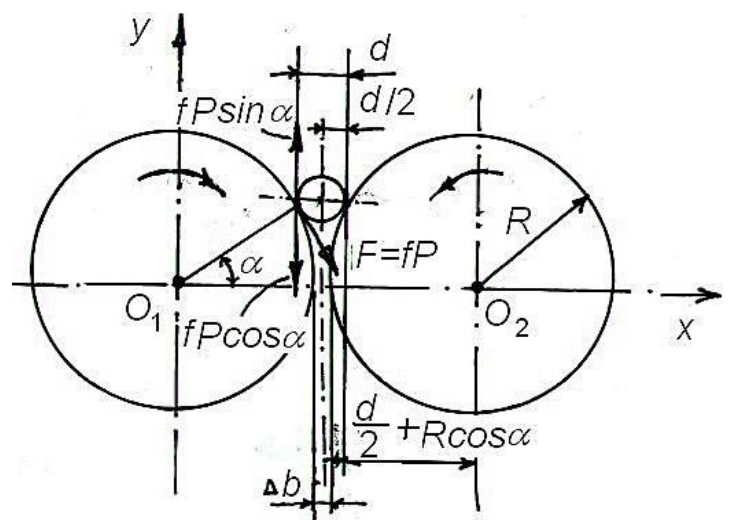

Figure 2. Forces affecting the grain flow between the rolls in the vertical delivery.

Thus, if we write down the vertical trajectories of $y$ axle for the forces affecting the grain, we will obtain the condition of the grain capture and pulling with the drums:

$2 p \sin \alpha-2 f P \cos \alpha=0$,

Hence, we can find out the friction force:

$f=\sin \alpha / \cos \alpha=\operatorname{tg} \alpha$,

On the other hand, Figure 2 shows:

$O_{1} O_{2}=D+\Delta b=2 R \cos \alpha+d$,

Hence,

$D-2 R \cos \alpha=d-\Delta b$

or:

$D(1-\cos \alpha)=d-\Delta b$.

According to the last expression, we can write down the drum diameter value satisfying the above condition:

$D=\frac{d-\Delta b}{1-\cos \alpha}$

This expression is identical to that found above (9). Here, $D$ is the drum diameter; $d$-average grain diameter or thickness at the inlet; $\Delta d$ - grain thickness after pressing; $\alpha$ - capture angle of the grain at the initial moment.

In order fully to capture and press the grain, its value will be equal to the angle of friction $\varphi$ between the drum and grain, $\alpha=\varphi$. That is why, the last formula can be represented as follows:

$D=\frac{d-\Delta b}{1-\cos \phi}$.

From the two above mentioned options, it is more reasonable to choose the vertical flow system for the small-size grinding mill. Thus, in this installation and according to this chart, the grain can be delivered from the hopper into the drum, both free and forced. In addition, the potential energy during the vertical grain delivery $(m, g, h)$ is used in the course of the process. Using the last formula, the drum diameter of the smallsize grain grinding mill can be determined for real conditions.

If the grain thickness before pressing is $d=4.4 \mathrm{~mm}$ and size after pressing is $\Delta b=2.2 \mathrm{~mm}$, and the friction coefficient is $\operatorname{tg} \varphi=f=0.4$ to be introduced into the last expression and calculated, we can establish that each drum should be $D>17.4 \mathrm{~mm}$ in order the drums could capture the grain and press it in between. That is why, it is reasonable to choose the drum with the diameter exceeding this limit for the small-size grain grinding mill. The effect of various moisture on the grain seed grinding process with pressing is studied in separate options. The results are presented in Table 1. It was established that the moisture increase is observed in all cases when the energy consumption for the grain seed pressing and for consistent operation reduces.

As the moisture decreases, a decrease in the required energy consumption and energy consumption per unit of work is required by an extensive law. Energy consumption for barley pressing with decreasing moisture. 
Table 1. General energy consumption and energy consumption for consistent operation during pressing on the smallsize grain grinding mill.

\begin{tabular}{|c|c|c|c|c|c|c|}
\hline Moisture, \% & 15 & 20 & 25 & 30 & 35 & 40 \\
\hline \multicolumn{7}{|c|}{ General energy consumption, $\mathrm{N}$} \\
\hline barley & 2.05 & 1.47 & 1.10 & 0.88 & 0.72 & 0.58 \\
\hline wheat & 1.95 & 1.38 & 1.02 & 0.75 & 0.57 & 0.45 \\
\hline corn & 1.88 & 1.30 & 0.93 & 0.68 & 0.45 & 0.35 \\
\hline wheat oat & 1.81 & 1.25 & 0.85 & 0.47 & 0.35 & 0.20 \\
\hline \multicolumn{7}{|c|}{ Energy consumption for consistent operation, $\mathrm{q}$} \\
\hline barley & 0.0175 & 0.0078 & 0.0030 & 0.0015 & 0.0011 & 0.0010 \\
\hline wheat & 0.0165 & 0.0075 & 0.0028 & 0.0013 & 0.0012 & 0.0085 \\
\hline corn & 0.0160 & 0.0070 & 0.0022 & 0.0010 & 0.0008 & 0.0006 \\
\hline wheat oat & 0.0152 & 0.0065 & 0.0020 & 0.0008 & 0.0005 & 0.0003 \\
\hline
\end{tabular}

On moisture $W$ : 1 - $1^{1}$ - barley; 2 - $2^{1}$-wheat; 3 - $3^{1-}$ corn; $4-41-$ wheat oat reduces from $15 \%$ to $40 \%, 2.05$ : $0.58=3.53$ times; for wheat pressing $-1.95: 0.45=4.3$ times; for corn pressing - 1.88: $0.35=5.37$ times; for pea pressing $-1.81: 0.20=9.05$ times. However, it can be concluded that when the grain was pre-moistened and ground before feeding, it was found that with the grain moisture of more than $25 \%$ in all cereals, a fraction of less than $1 \mathrm{~mm}$ is observed. Consequently, the most effective mode, both zootechnically and energetically, is the moisture between 25 and 35\%. Therefore, it will be better if the nutritious grain feeds are moistened within these limits before feeding and pressed on the unit offered. In experimental studies, the percentage of fine fractions less than $1 \mathrm{~mm}$ was investigated when grinding various types of cereals at different moisture levels (Table 2). It was established that in barley, with the moisture of $15-20 \%$, there are $0.8-0.3 \%$ of fractions less than $1 \mathrm{~mm}$, and with the moisture of more than 30 , there are no fractions less than $1 \mathrm{~mm}$. Wheat-fractions less than $1 \mathrm{~mm}$ with the moisture of $15-20 \%-0.8-0.4 \%$, respectively. Corn-fractions less than $1 \mathrm{~mm}-15-20-$ $25 \%$ with the moisture of $1.5-0.85-0.2 \%$. Once the moisture of $25 \%$ is reached, the powder fraction is observed in the corn (Table 3). When pressing individual grains at different moisture levels, the effect of moisture on the degree of pressing was studied, and Table 2 and Table 3 show that, due to the influence of the same force, the grains of different moisture content are pressed to different degrees, and their contact points increase. For example, for the original surface of barley, this extends in the surface area increases by 2.8 at the moisture content of $15 \%$ to $40 \%$; for wheat -3.2 ; for corn -3.5 , or more.

Table 2. Change dynamics for fractions less than $1 \mathrm{~mm}$ and pressed grain surface extend at various moisture values with a pressure coefficient for various cereals.

\begin{tabular}{|c|c|c|c|c|c|c|c|}
\hline \multirow{2}{*}{ Kind of grain } & \multicolumn{7}{|c|}{ Moisture, \% } \\
\hline & 15 & 20 & 25 & 30 & 35 & 40 & moisture \\
\hline \multicolumn{8}{|c|}{ fractions less than $1 \mathrm{~mm}, \%$} \\
\hline barley & 0.8 & 0.3 & 0.020 & - & - & - & \\
\hline wheat & 0.8 & 0.4 & 0.025 & - & - & - & \\
\hline corn & 1.30 & 1.75 & 0.2 & - & - & - & \\
\hline \multicolumn{8}{|c|}{ pressed grain surface extends, times } \\
\hline barley & 1 & 1.3 & 1.8 & 2.0 & 2.5 & 2.8 & \\
\hline wheat & 1 & 1.25 & 1.9 & 2.2 & 2.8 & 3.2 & \\
\hline corn & 1 & 1.50 & 1.95 & 2.1 & 3.0 & 3.5 & \\
\hline
\end{tabular}


Table 3. Grain particle size of cereals of different moisture content ground and pressed on the experimental unit.

\begin{tabular}{lccccccccc}
\hline Kind of grain & \multicolumn{3}{c}{ Wheat } & \multicolumn{3}{c}{ Barley } & \multicolumn{3}{c}{ Corn } \\
\hline Moisture & $40 \%$ & $30 \%$ & $40 \%$ & $20 \%$ & $30 \%$ & $40 \%$ & $20 \%$ & $30 \%$ & $40 \%$ \\
\hline Dimensions: & & & & & & & & & - \\
Up to $1.0 \mathrm{~mm}$ & 0.8 & - & - & 0.4 & - & - & 0.6 & - & - \\
Up to $1.1 \ldots 2.0 \mathrm{~mm}$ & 1.4 & 1.1 & 1.0 & 1.5 & 1.2 & 1.1 & 1.3 & 1.1 & 0.9 \\
Up to $2.1 \ldots 3.0 \mathrm{~mm}$ & 4.0 & 3.9 & 3.8 & 4.1 & 3.8 & 3.1 & 4.8 & 3.0 & 2.1 \\
Up to $3.1 \ldots 4.0 \mathrm{~mm}$ & 11.9 & 10.0 & 9.2 & 12 & 10.0 & 8.8 & 11.2 & 10.9 & 8.0 \\
Up to $4.1 \ldots 5.0 \mathrm{~mm}$ & 28.0 & 30.0 & 27.0 & 30.0 & 25.0 & 22.0 & 33.1 & 34.0 & 30.0 \\
More than $5.0 \mathrm{~mm}$ & 54 & 55 & 59 & 52.0 & 60.0 & 65.0 & 49.0 & 51 & 59.0 \\
\hline Not pressed, whole & 0 & 0 & 0 & 0 & 0 & 0 & 0 & 0 & 0 \\
\hline
\end{tabular}

\section{CONCLUSIONS}

Therefore, it was found that moistening in the process of the grain pressing promotes both for energy consumption and extend in the contact surface, and reduction of powder fractions less than $1 \mathrm{~mm}$. That is why, it will be more effective if the grain is moistened before feeding, held for some time ( 24 hours), and then pressed on the unit offered. Table 3 shows the changes in the grain size distribution in the process of pressing depending on the different moisture content. As it can be seen from the table, the full grain pressing is achieved, no whole grain remains in the process. With the above and suggested distances between the drums, the bulk of the pressed grain core is $1.5-2$ or more thin layers pressed. This is considered to be a digestible mass for animals according to the zootechnical requirement.

The design and process parameters of the small-size, low energy-intensive unit for feed oakum production functioning on the basis of the flattening principle and used in the farming enterprises have been substantiated. From the theoretical point of view, the research work is aimed at plotting the analytical dependences for the selected design and process option of the roll flattening mill of the required capacity with substantiation of design and process parameters for various grain mix compositions. The theoretical research results made it possible to substantiate the reasonable design of the roll flattening mill to ensure the feed flakes quality with less power consumption.

\section{REFERENCES}

Afanasyev, P. A. 1983. 1983. Grinding mills. Machinostroeniye, Moscow.

Andrianov, A. M. 1972. Effect of the mode of feeding on the maximum capacity of the corn-flattening mill. Notes of Voronezh Agricultural Institute named after K.D. Glinka 53: 226-227.

Ankulenko, K. E. 2003. Equipment for grain processing enterprises. Feeds, 8: 27-28.

Babaev, A. I. 2003. Farmers' diary. Hyandzhlyk, Baku.

Baldanov, M. B. and N. S. Khusaev. 2002. Test methods of small-size multipurpose feed grinding mill. Materials of the Scientific and Practical Conference "Higher agricultural education, agricultural science and practice - the development of the agro-industrial complex of the Baikal region". Publishing House BGSKhA, UlanUde.

Baranov, L. 1999. Experience in High quality feed preparation. Agricultural News, 1: 21-22.

Baranov, L. N. 2000. High quality feed preparation technology. Tractors and Agricultural Machinery, 4: 11-48.

Baranov, L. N. 2004. Corn-flattening and packing machine. Agricultural News, 3: 2-10.

Deshko, V. I. 1976. Study of the wet grain flattening process. Agricultural Mechanization and Electrification, 35: 98-235.

Deshko, V. I. and G. M. Kukta. 1991. Performance indicators of the wet grain flattening mill. Agricultural mechanization and electrification. Journal of Pig Breeding, 2: 3-11.

Dorofeev, N. S. and A. A. Sundeev. 1978. Study of technology methods of the wet grain flattening. Energy, dynamics, wear and repair of agricultural machinery. Scientific Works of Voronezh Agricultural Institute named after K.D. Glinka, 99.

Mammadova, G. A. and B. M. Bagirov. 2008. Research of small-sized drum-type seawater device. Materials of AzTU Scientific-practical conference. AzTU, Ganja.

Pilipenko, A. N. 1981. Calculation method for the grain 
flattening mill process parameters. Research and design of machines for livestock farming and feed production. , 6: 36-42. Collection of Scientific Works VNIIZHIVMASH, 6.
Rudovsky, P. H., M. N. Nuriyev and I. S. Recebov. 2019. Preparation of flax roving for spinning in electrochemical activated solutions. 6(138): 34-38. Fibres \&Textiles in Eastern EUROPE, 6: 34-38.

Publisher's note: EScience Press remains neutral with regard to jurisdictional claims in published maps and institutional affiliations.

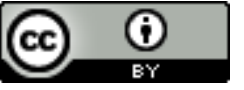

Open Access This article is licensed under a Creative Commons Attribution 4.0 International License, which permits use, sharing, adaptation, distribution and reproduction in any medium or format, as long as you give appropriate credit to the original author(s) and the source, provide a link to the Creative Commons license and indicate if changes were made. The images or other third-party material in this article are included in the article's Creative Commons license, unless indicated otherwise in a credit line to the material. If material is not included in the article's Creative Commons license and your intended use is not permitted by statutory regulation or exceeds the permitted use, you will need to obtain permission directly from the copyright holder. To view a copy of this license, visit http://creativecommons.org/licenses/by/4.0/. 